\title{
PRODUTIVIDADE DA MARCELA [Achyrocline satureioides (Lam.) DC.] EM CULTIVO SOLTEIRO E CONSORCIADO COM TANSAGEM (Plantago major L. )
}

\author{
Productivity of "marcela" [Achyrocline satureioides (Lam.) DC.] in a \\ monocrop and intercropped with common plantain (Plantago major L.)
}

\author{
Ana Cristina Araújo Ajalla ${ }^{1}$, Maria do Carmo Vieira², \\ Néstor A. Heredia Zarate ${ }^{2}$, José Hortêncio Mota ${ }^{3}$, Thalita Martinhão de Souza ${ }^{4}$
}

\begin{abstract}
RESUMO
Objetivou-se, neste trabalho, avaliar o crescimento e a produção de biomassa de marcela [Achyrocline satureioides (Lam.) DC.], em cultivo solteiro e consorciado com tansagem (Plantago major L.) e determinar a população de plantas dessas espécies medicinais, em consorciação mais eficiente, visando o aumento produtivo e retorno econômico. Foram constituídos seis tratamentos: duas fileiras de marcela espaçadas de $0,40 \mathrm{~m}\left(\mathrm{M}_{0,40}\right)$; duas fileiras de marcela espaçadas de $0,25 \mathrm{~m}\left(\mathrm{M}_{0.25}\right)$; duas fileiras de tansagem espaçadas de $0,75 \mathrm{~m}\left(\mathrm{~T}_{0,75}\right)$; três fileiras de tansagem espaçadas de $0,40 \mathrm{~m}\left(\mathrm{~T}_{0,40}\right)$; duas fileiras de marcela alternadas com três fileiras de tansagem $\left(\mathrm{M}_{0,40} \mathrm{~T}_{0.40}\right)$ e duas fileiras de marcela alternadas com duas fileiras de tansagem $\left(\mathrm{M}_{0.25} \mathrm{~T}_{0.75}\right)$. O delineamento experimental foi em blocos casualizados, com quatro repetições. Foram efetuadas colheitas de marcela aos 180, 210 e 225 dias após o transplante. Os tratamentos não influenciaram as alturas das plantas da marcela e da tansagem. As produções da marcela foram influenciadas apenas pelas três épocas de colheita sendo significativamente superior nas duas primeiras, apresentando massas de flores frescas de 2,51, 2,63 e 1,28 tha-1 , respectivamente, aos 180, 210 e 225 dias após o transplante. A massa de folhas frescas da tansagem não foi influenciada pelo consórcio mas foi maior sob o espaçamento $\mathrm{T}_{0,40}\left(6,13 \mathrm{t} \mathrm{ha}^{-1}\right)$ do que sob o $\mathrm{T}_{0,75}\left(3,32 \mathrm{t}\right.$ ha $\left.\mathrm{a}^{-1}\right)$. A Razão de Área Equivalente do consórcio $\mathrm{M}_{0,40} \mathrm{~T}_{0,40}$, foi 1,6 e o de $\mathrm{M}_{0,25} \mathrm{~T}_{0,75}$ foi 2,4. Quanto à renda bruta observaram-se acréscimos de $30 \%$ para $\mathrm{o}$ tratamento $\mathrm{M}_{0,40} \mathrm{~T}_{0,40}$ e $77 \%$ para o tratamento $\mathrm{M}_{0,25} \mathrm{~T}_{0,75}$ comparadas ao tratamento da marcela solteira $\mathrm{M}_{025}$ e de $70 \%$ e $131 \%$, respectivamente, em relação à tansagem solteira $\mathrm{T}_{0,40}$.
\end{abstract}

Termos para indexação: Planta medicinal, associação de culturas, população de planta, marcela, Achyrocline satureioides, tansagem, Plantago major.

\section{ABSTRACT}

The objective of this work was to evaluate the growth and the yield of marcela [Achyrocline satureioides (Lam.) DC.] biomass, in a monocrop system and intercropped with common plantain (Plantago major L.) as well as to determine the population of these medicinal plants in a more efficient intercrop system, in order to increase the yield and the economic return. Six treatments were established: two rows of marcela spaced $0.4 \mathrm{~m}$ from each other $\left(\mathrm{M}_{0.40}\right)$, two rows of marcela spaced $0.25 \mathrm{~m}\left(\mathrm{M}_{0.25}\right)$, two rows of common plantain spaced $0.75 \mathrm{~m}\left(\mathrm{~T}_{075}\right)$, three rows of common plantain spaced $0.40 \mathrm{~m}\left(\mathrm{~T}_{040}\right)$, two rows of marcela alternated with three rows of common plantain $\left(\mathrm{M}_{0.40} \mathrm{~T}_{0.40}\right)$, and two rows of marcela alternated with three rows of common plantain $\left(\mathrm{M}_{0.25} \mathrm{~T}_{0.75}\right)$. The experimental design was the randomized blocks with four replications. Harvests of marcela were performed at 180, 210 and, 225 days after the transplantation. The treatments did not influence the heights of marcela and common plantain. Yields of marcela were influenced only by the harvest dates and they were significantly higher in the first and the second dates, showing fresh mass of flowers of 2.51;2.63 and $1.28 \mathrm{tha}^{-1}$, respectively, at 180,210 and 225 days after the transplantation. Fresh mass of common plantain leaves was not influenced by the intercropping, but it was higher under $\mathrm{T}_{0.40}\left(6.13 \mathrm{tha}^{-1}\right)$ space than under $\mathrm{T}_{0.75}\left(3.32 \mathrm{t} \mathrm{ha}^{-1}\right)$. Land Equivalent Ratio of the $\mathrm{M}_{0.40} \mathrm{~T}_{0.40}$ intercropping was 1.6 and that of $\mathrm{M}_{0.25} \mathrm{~T}_{0.75}$ was 2.4. Regarding the gross income, increases of $30 \%$ were observed for the treatment $\mathrm{M}_{0.40} \mathrm{~T}_{0.40}$ and $77 \%$ for the treatment $\mathrm{M}_{0.40} \mathrm{~T}_{0.40}$ when compared to the treatment $\mathrm{M}_{0.25}$ and $70 \%$ and $131 \%$, respectively, when compared to $\mathrm{T}_{0.40}$

Index terms: Medicinal plant, intercropping, plant population, marcela, Achyrocline satureioides, common plantain, Plantago major.

(Recebido em 5 de junho de 2007 e aprovado em 30 de abril de 2008)

\footnotetext{
${ }^{1}$ Engenheira Agrônoma, Mestre em Agronomia - Centro de Pesquisa e Capacitação Rural/CEPAER - Agência de Desenvolvimento Agrário e Extensão Rural/AGRAER - Rodovia MS 080, Km 10 - Cx. P. 472 - 79114-000 - Campo Grande, MS - acaa337@hotmail.com

'Engenheiros Agrônomos, Doutores em Fitotecnia, Professores - Faculdade de Ciências Agrárias/FCA - Universidade Federal de Grande Dourados/ UFGD - Rodovia Dourados a Itahum, Km 12 - Cx. P. 533 - 79804-970 - Dourados, MS - vieiracm@terra.com.br; nahz@terra.com.br. Bolsistas de Produtividade em Pesquisa do CNPq.

${ }^{3}$ Engenheiro Agrônomo, Doutor - Campi São Vicente - Instituto Federal de Educação, Ciência e Tecnologia do Mato Grasso/IFET Mato Grosso - Br 364, Km 329 - São Vicente da Serra - 78106-970 - Santo Antônio do Leverger, MT - hortenciomota@terra.com.br

${ }^{4}$ Graduanda em Agronomia - Faculdade de Ciências Agrárias - Universidade Federal da Grande Dourados/UFGD - Rodovia Dourados a Itahum, Km 12 Cx. P. 533 - 79804-970 - Dourados, MS - thalitamartinhao@hotmail.com - Bolsista de iniciação científica PIBIC/CNPq
} 


\section{INTRODUÇÃO}

A marcela [Achyrocline satureioides (Lam) DC, Asteraceae] tem ocorrência em todo o Brasil, exceto na região Amazônica, crescendo espontaneamente em pastagens e beiras de estradas, campos sujos, campos limpos e em cerrado ralo. É indicada na medicina popular para problemas digestivos, males do fígado, epilepsia; é também sudorífera, antiinflamatória, antiespasmódica, calmante, sedativa, emenagoga, para cólicas de origem nervosa, contra prisão de ventre e diarréia (ALMEIDA et al., 1998; LORENZI \& MATOS, 2002). Estudos farmacológicos comprovaram as propriedades digestivas, colagoga, eupéptica, antiespasmódica, carminativa, antiinflamatória e emenagoga (SIMÕES et al., 1989). Dentre os componentes químicos, na marcela foram observados flavonóides, sesquiterpenos e monoterpenos e polissacarídeos imunoestimulantes (ALMEIDA et al., 1998; LORENZI \& MATOS, 2002).

A planta de tansagem (Plantago major L., Plantaginaceae) é bianual ou semiperene e vegeta espontaneamente em áreas de pastagens, terrenos cultivados e em locais sombreados e úmidos (CORRÊA JÚNIOR et al., 1994; LORENZI \& MATOS, 2002), é usada popularmente como diurética, antidiarréica, expectorante, hemostática, cicatrizante, adstringente, emoliente e depurativa, sendo empregada contra infecções das vias respiratórias, bronquites e úlcera péptica. Sua composição química inclui aucubosídio, goma, mucilagem, resina, tanino, flavonóides (alantoína), iridóides, fenólicos (plantaginina e plantamajosina), esteróides, ácidos orgânicos e alcalóides. Um estudo quanto às quantidades de proteínas e vitaminas das folhas de Plantago as classificam como alimentícias (CORRÊA, 1984; CORRÊA JÚNIOR et al., 1994; FONT QUER, 1993; LORENZI \& MATOS, 2002; MARCHESAN et al., 1998; PENNA, 1946; SAKER \& KAWASHITY, 1998). Os estudos sobre a tansagem comprovam ação antinociceptiva (SANTOS \& CASTRO, 1994), antisecretora gástrica e antiulcerogênica (GUILLEN et al., 1994a) além de propriedades antiedematogênica e analgésica (GUILLEN et al., 1994b).

Do ponto de vista agronômico e pragmático, assume-se que duas culturas são adequadas para serem consorciadas se o Índice de Eficiência da Terra (IET) ou a Razão de Área Equivalente (RAE) resultante for maior que 1,0. Isso indica que a RAE ou IE avaliam a eficiência do consórcio de culturas, em relação aos monocultivos, para as produções em monocultivo se igualarem às de um hectare das mesmas culturas em associações (VIEIRA, 1989). Negreiros et al. (2002), destacam que o consórcio de cultura é prática tradicional na produção de alimentos em regiões tropicais de pequenas propriedades, onde o objetivo dessas associações tem sido de otimizar a utilização de recursos ambientais, de área e de mão-deobra. Sullivan (2001) cita que o aumento da produtividade por unidade de área é uma das razões mais importantes para se cultivar duas ou mais culturas juntas, devendo ser considerados os fatores de cultivo como densidade e arranjo de plantas visando a diminuição da competição por água, luz e nutrientes bem como maximizar possíveis efeitos benéficos entre as espécies.

Objetivou-se, neste trabalho, avaliar o crescimento e a produtividade de biomassa de Achyrocline satureioides (Lam.) DC. (marcela) em cultivo solteiro e consorciado com Plantago major L. (tansagem) e determinar a população de plantas dessas espécies medicinais em consorciação mais eficiente, visando o aumento produtivo e retorno econômico.

\section{MATERIAL E MÉTODOS}

O trabalho foi desenvolvido no Horto de Plantas Medicinais - HPM, (S 22 $11^{\circ} 43.7^{\prime \prime}$ W 054 56' 08. 5") da Universidade Federal de Mato Grosso do Sul (UFMS), em Dourados - MS, no período de maio de 2004 a maio de 2005. O clima, segundo Köppen (MATO GROSSO DO SUL, 1990), é classificado como Mesotérmico Úmido; do tipo Cwa, com precipitações médias anuais de $1500 \mathrm{~mm}$. As temperaturas máximas e mínimas e as precipitações, encontram-se na Figura 1. O solo é do tipo Latossolo Vermelho distroférrico (EMBRAPA, 1999), textura argilosa, originalmente sob vegetação de Cerrado. Os resultados da análise química da amostra do solo, segundo metodologia do Laboratório de Solos da UFMS, foram: $\mathrm{pH}$ $\mathrm{H}_{2} \mathrm{O}(1: 2,5)=5,7 ; \mathrm{P}\left(\mathrm{mg} \mathrm{dm}^{-3}\right)=1,6$ (extrator Mehlich-1); K $\left(\mathrm{mmol} \mathrm{dm}^{-3}\right)=2,8 ; \mathrm{Al}^{+3}\left(\mathrm{mmol}_{\mathrm{c}} \mathrm{dm}^{-3}\right)=1,8 ; \mathrm{Ca}^{+2}\left(\mathrm{mmol}_{\mathrm{c}} \mathrm{dm}^{-3}\right)=$ 35,$3 ; \mathrm{Mg}\left(\mathrm{mmol}_{\mathrm{c}} \mathrm{dm}^{-3}\right)=14,3 ; \mathrm{H}+\mathrm{Al}\left(\mathrm{mmol}_{\mathrm{c}} \mathrm{dm}^{-3}\right)=65 ; \mathrm{SB}$ $\left(\mathrm{mmol} \mathrm{dm}^{-3}\right)=52,4$.

A marcela e a tansagem foram alocadas no campo em experimento conjunto, sendo constituídos seis tratamentos da seguinte forma: duas fileiras solteiras de marcela espaçadas de $0,40 \mathrm{~m}\left(\mathrm{M}_{0,40}\right)$; duas fileiras solteiras de marcela espaçadas de $0,25 \mathrm{~m}\left(\mathrm{M}_{0,25}\right)$; duas fileiras solteiras de tansagem espaçadas de $0,75 \mathrm{~m}\left(\mathrm{~T}_{0,75}\right)$; três fileiras solteiras de tansagem espaçadas de $0,40 \mathrm{~m}$ $\left(\mathrm{T}_{0,40}\right)$; duas fileiras de marcela espaçadas de $0,40 \mathrm{~m}$ consorciada com três fileiras de tansagem $\left(\mathrm{M}_{0,40} \mathrm{~T}_{0,40}\right)$ e duas fileiras de marcela espaçadas de $0,25 \mathrm{~m}$ consorciada com duas fileiras de tansagem $\left(\mathrm{M}_{0,25} \mathrm{~T}_{0,75}\right)$. O delineamento experimental foi de blocos casualizados, com quatro repetições. As diferentes épocas de colheita 


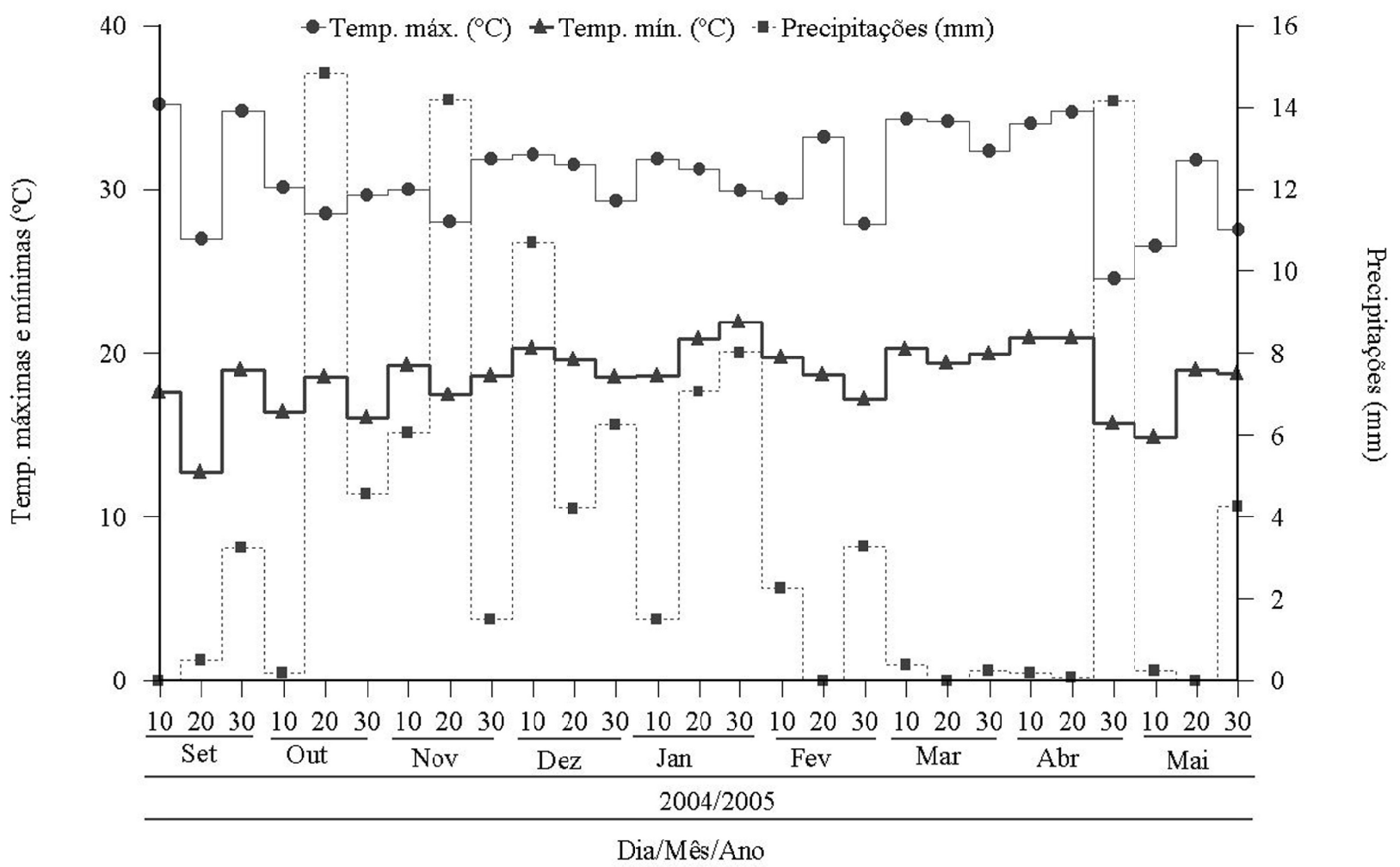

Figura 1 - Média de temperaturas máximas e mínimas e precipitação total no período setembro de 2004 a maio de 2005, por decêndio. Posto de observação meteorológico da UFMS. Dourados-MS.

da marcela foram avaliadas como parcelas subdivididas no tempo. Os espaçamentos entre plantas foram de 0,40 $\mathrm{m}$ para a marcela e $0,30 \mathrm{~m}$ para a tansagem. A área total de cada parcela foi de $3,6 \mathrm{~m}^{2}(1,5 \mathrm{~m}$ de largura $\mathrm{x} 2,4 \mathrm{~m}$ de comprimento) e a área útil, de $2,4 \mathrm{~m}^{2}(1,0 \mathrm{~m}$ de largura $\mathrm{x}$ 2,4 $\mathrm{m}$ de comprimento).

As mudas foram produzidas a partir de sementes, colocadas em bandejas de isopor de 128 células, preenchidas com substrato preparado na base de solo, areia e cama-de-frango semidecomposta nas proporções 3:1:1. As mudas foram transplantadas com 126 e 45 dias, com $15 \mathrm{~cm}$ e $5 \mathrm{~cm}$ de altura para marcela e tansagem, respectivamente. Durante o ciclo de cultivo, foram efetuadas irrigações por aspersão e controle manual das plantas infestantes. Não foram feitas adubações e calagem. Foram medidas as alturas de todas as plantas, em cada parcela, a partir de 30 dias após o transplante - DAT. Para a tansagem, a altura foi medida a cada 15 dias, até 75 DAT e para a marcela, a cada 15 dias, até 210 DAT.

Foram colhidas duas plantas inteiras da marcela em três épocas: 180, 210 e 225 DAT, quando avaliaram-se as massas de flores frescas e secas e das partes aéreas sem flores. Foram colhidas todas as flores de tansagem no início do florescimento, aos 75 DAT, e avaliadas as massas de folhas frescas e secas, a área foliar, o número e as massas das inflorescências frescas e secas.

Às médias dos dados de altura de plantas da marcela e tansagem foram ajustadas equações de regressão em função dos dias após transplante, para cada tratamento. Os demais dados foram submetidos à análise de variância, aplicando-se teste $\mathrm{F}$ e Tukey, até $5 \%$ de probabilidade.

O consórcio foi avaliado utilizando-se a expressão da Razão de Área Equivalente (RAE), proposta por Caetano et al. (1999), a saber: $\mathrm{RAE}=\left(\mathrm{Mc} \cdot \mathrm{Ms}^{-1}\right)+\left(\mathrm{Tc} \cdot \mathrm{Ts}^{-1}\right)$. Onde: Mc - cultivo da marcela consorciada; Ms - cultivo da marcela solteira; Tc - cultivo da tansagem consorciada e Ts - cultivo da tansagem solteira. A renda bruta foi calculada com base em informações de preço fornecidas pelo Laboratório Industrial Vida e Saúde Ltda - "Chá Chileno", considerando-se valores pagos ao produtor, pesquisados em julho de 2006, sendo de $R \$ 8,00 \mathrm{~kg}^{-1}$ e $\mathrm{R} \$ 6,00 \mathrm{~kg}^{-1} \mathrm{de}$ flores secas de marcela e de folhas secas de tansagem, respectivamente. 


\section{RESULTADOS E DISCUSSÃO}

Para cada época analisada, não houve diferença significativa entre os tratamentos em relação à altura das plantas de marcela. A marcela apresentou em todos os tratamentos resposta de crescimento quadrática (Figura 2), atingindo média de $0,68 \mathrm{~m}$ aos 210 dias. As alturas foram menores que as obtidas por Vieira et al. (2001), que ao analisarem crescimento e produção de marcela em função de espaçamentos $(0,40 \mathrm{~m} ; 0,50 \mathrm{~m} ; 0,60 \mathrm{~m})$ e arranjo de plantas (duas e três fileiras), observaram aos 180 dias média de $0,80 \mathrm{~m}$ e, na colheita, aos 240 dias, alturas máximas de $1,51 \mathrm{~m}(0,40 \mathrm{~m}$ entre plantas e duas fileiras $)$ a $1,78 \mathrm{~m}(0,50$ $\mathrm{m}$ e duas fileiras).

A produtividade de massa fresca e seca da marcela, tanto da parte aérea quanto das flores, não diferiu significativamente em função do consórcio e nem dos espaçamentos (Tabelas 1 e 2), bem como não houve interação entre os tratamentos, demonstrando que os cultivos mais adensados para essa cultura não causariam diminuição na produção.

Em relação à época de colheita (Tabela 2), as produções de massa seca de parte aérea sem flores e massas de flores frescas e secas, obtidas aos 180 DAT e 210 DAT foram superiores àquelas obtidas aos 225 DAT. Sendo a marcela uma planta considerada de ciclo anual, este resultado indica que após esse período, a planta entrou na fase de senescência e, por isso, diminuiu a produção de flores e folhas.

Em relação à tansagem, houve diferença significativa entre os tratamentos na altura de plantas que apresentou resposta de crescimento quadrática, com maiores variações nas taxas de crescimento dependente dos tratamentos, entre 25 e 60 DAT (Figura 3). A altura máxima foi de $10,81 \mathrm{~cm}$, aos 56 dias após o transplante, quando cultivadas em consórcio com a marcela, sob espaçamento de $0,75 \mathrm{~m}$ entre plantas.

O consórcio não influenciou significativamente a produtividade da tansagem (Tabela 3). Por outro lado, o arranjo sob três fileiras por canteiro, espaçadas de $0,40 \mathrm{~m}$, apresentou resultado de produtividade significativamente superior ao arranjo sob duas fileiras, indicando que a espécie pode ser cultivada em maiores densidades populacionais.

A maior área foliar observada (Tabela 3) sob arranjo de três fileiras, aliada com o melhor resultado de massa fresca e seca de folhas, indica que, neste experimento, a tansagem apresentou tolerância ao sombreamento. Mota et al. (2006), ao estudarem tansagem sob três e quatro fileiras consorciada com Pfaffia glomerata L. (fafia), não observaram diferenças significativas de área foliar e massa de folhas frescas e secas em relação ao arranjo de plantas. Por outro lado, o consórcio com a fafia, diminuiu significativamente a capacidade produtiva total da tansagem em função da competição entre as espécies por água, luz e nutriente, resultando em menor produtividade

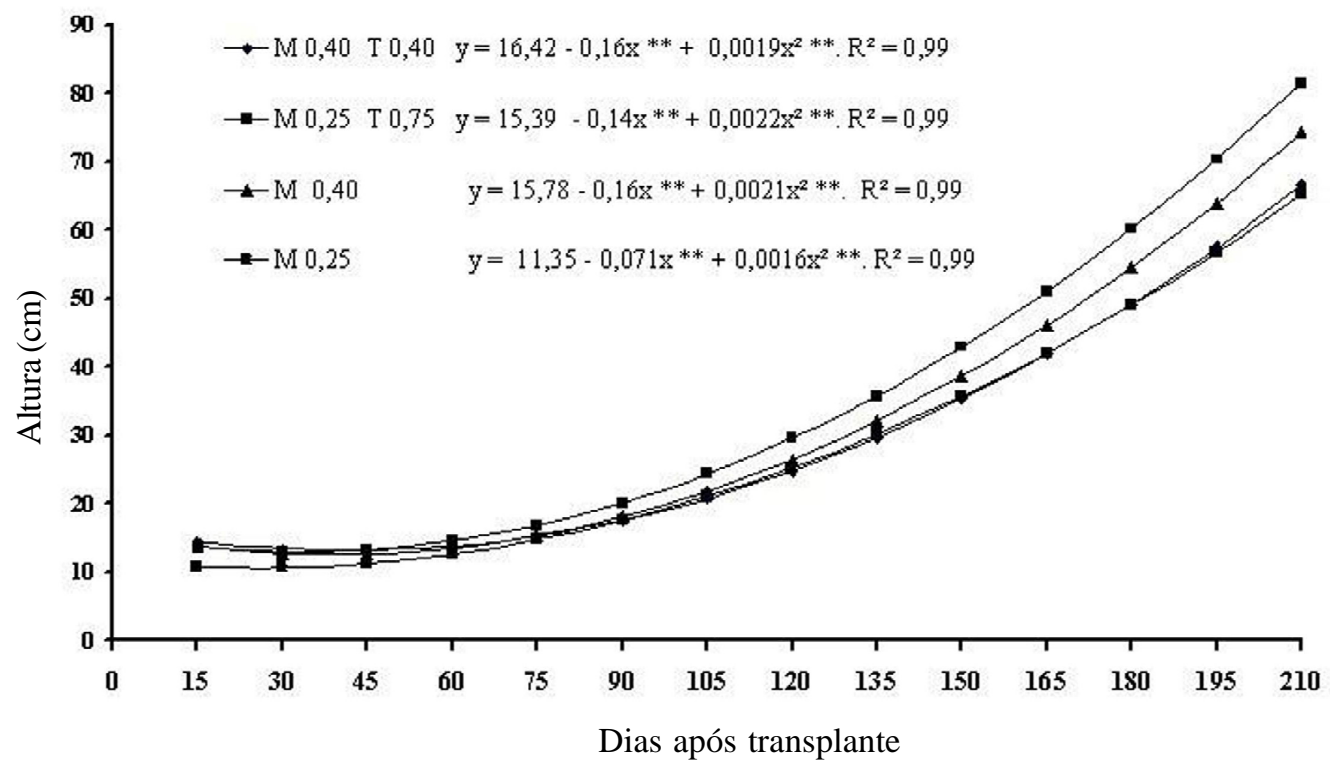

Figura 2 - Altura de plantas de marcela em função do sistema de cultivo (solteiro e consorciado), arranjos de plantas e espaçamentos, no decorrer do ciclo. UFMS, Dourados, 2004-2005. 
Tabela 1 - Produtividade ( $\mathrm{t} \mathrm{ha}^{-1}$ ) de massa fresca (MFF) e seca de flores (MSF) e massa fresca (MFPA) e seca da parte aérea sem flores (MSPA) da marcela cultivada solteira e consorciada com tansagem, sob dois espaçamentos entre fileiras, colhidas em três épocas (dias após o transplante - DAT). UFMS, Dourados, 2004-2005.

\begin{tabular}{|c|c|c|c|c|}
\hline 180 DAT & MFF & MSF & MFPA & MSPA \\
\hline \multicolumn{5}{|l|}{ Arranjo de plantas } \\
\hline Solteiro & $2,40 \mathrm{a}$ & $1,00 \mathrm{a}$ & $23,89 \mathrm{a}$ & 8,89 a \\
\hline Consorciado & $2,59 \mathrm{a}$ & $0,98 \mathrm{a}$ & 23,66 a & $8,45 \mathrm{a}$ \\
\hline \multicolumn{5}{|c|}{ Espaçamento entre fileiras } \\
\hline $0,40 \mathrm{~m}$ & $2,00 \mathrm{a}$ & $0,78 \mathrm{a}$ & $22,70 \mathrm{a}$ & $7,33 \mathrm{a}$ \\
\hline $0,25 \mathrm{~m}$ & $3,03 \mathrm{a}$ & $1,19 \mathrm{a}$ & $25,28 \mathrm{a}$ & $10,01 \mathrm{a}$ \\
\hline $210 \mathrm{DAT}$ & MFF & MSF & MFPA & MSPA \\
\hline \multicolumn{5}{|l|}{ Arranjo de plantas } \\
\hline Solteiro & $2,15 \mathrm{a}$ & $0,99 \mathrm{a}$ & $21,10 \mathrm{a}$ & $7,37 \mathrm{a}$ \\
\hline Consorciado & $3,11 \mathrm{a}$ & $1,19 \mathrm{a}$ & $25,36 \mathrm{a}$ & $8,51 \mathrm{a}$ \\
\hline \multicolumn{5}{|c|}{ Espaçamento entre fileiras } \\
\hline $0,40 \mathrm{~m}$ & $2,22 \mathrm{a}$ & $0,96 \mathrm{a}$ & $22,22 \mathrm{a}$ & 7,58 a \\
\hline $0,25 \mathrm{~m}$ & $3,04 \mathrm{a}$ & $1,23 \mathrm{a}$ & $24,23 \mathrm{a}$ & $8,29 \mathrm{a}$ \\
\hline $225 \mathrm{DAT}$ & MFF & MSF & MFPA & MSPA \\
\hline \multicolumn{5}{|l|}{ Arranjo de plantas } \\
\hline Solteiro & $1,34 \mathrm{a}$ & $0,71 \mathrm{a}$ & $17,44 \mathrm{a}$ & $7,00 \mathrm{a}$ \\
\hline Consorciado & $1,22 \mathrm{a}$ & $0,64 \mathrm{a}$ & $15,59 \mathrm{a}$ & 5,98 a \\
\hline \multicolumn{5}{|c|}{ Espaçamento entre fileiras } \\
\hline $0,40 \mathrm{~m}$ & $1,30 \mathrm{a}$ & $0,63 \mathrm{a}$ & $15,50 \mathrm{a}$ & 6,39 a \\
\hline $0,25 \mathrm{~m}$ & $1,26 \mathrm{a}$ & $0,72 \mathrm{a}$ & $17,52 \mathrm{a}$ & $6,59 \mathrm{a}$ \\
\hline C.V. $(\%)$ & 48,80 & 47,28 & 32,14 & 28,10 \\
\hline
\end{tabular}

Médias seguidas pelas mesmas letras, nas colunas, para cada época e fator, não diferem, pelo teste $\mathrm{F}$, a 5\% de probabilidade.

Tabela 2 - Produtividade ( $\mathrm{t} \mathrm{ha}^{-1}$ ) de massas frescas (MFF) e secas de flores (MSF); massas frescas (MFPA) e secas da parte aérea (MSPA) de marcela, em três épocas de colheita. UFMS, Dourados, 2004-2005.

\begin{tabular}{ccccc}
\hline Dias após transplante & MFF & MSF & MFPA & MSPA \\
\hline 180 & $2,51 \mathrm{a}$ & $0,99 \mathrm{a}$ & $23,77 \mathrm{a}$ & $8,67 \mathrm{a}$ \\
210 & $2,63 \mathrm{a}$ & $1,09 \mathrm{a}$ & $23,23 \mathrm{a}$ & $7,94 \mathrm{a}$ \\
225 & $1,28 \mathrm{~b}$ & $0,68 \mathrm{~b}$ & $16,51 \mathrm{a}$ & $6,49 \mathrm{~b}$ \\
\hline C.V.(\%) & 48,80 & 47,28 & 32,14 & 28,10 \\
\hline
\end{tabular}

Médias seguidas pelas mesmas letras, nas colunas, não diferem, pelo teste Tukey, a 5\% de probabilidade.

em todas as características avaliadas para a tansagem consorciada com a fafia.

Os resultados da Razão de Área Equivalente RAE (Tabela 4) de 1,6 para o consórcio $\mathrm{M}_{0,40} \mathrm{~T}_{0,40}$ e 2,4 para o consórcio $\mathrm{M}_{0,25} \mathrm{~T}_{0,75}$, considerando massa de flores seca de marcela e massa de folhas seca de tansagem, indicam que os consórcios foram efetivos. E, que no monocultivo, as espécies exigiriam, respectivamente, $60 \%$ e $140 \%$ mais terras que sob consórcio. 


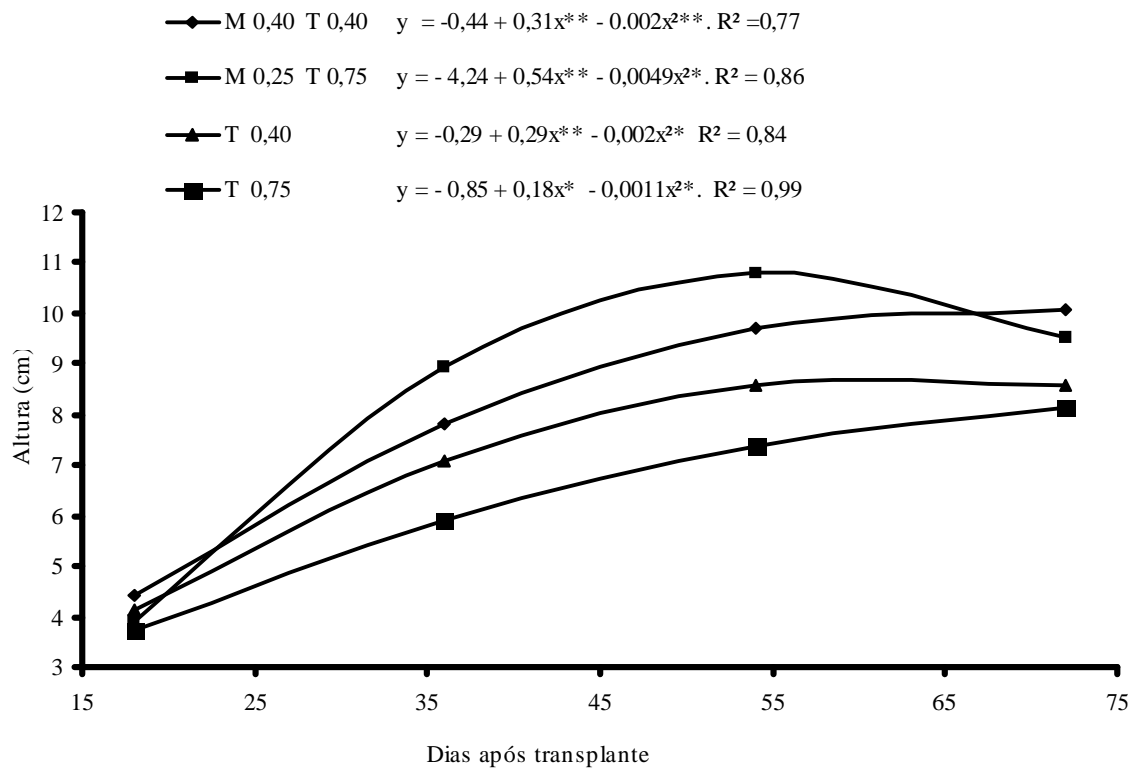

Figura 3 - Altura de plantas de tansagem em função do sistema de cultivo (solteiro e consorciado), arranjos de plantas e espaçamentos, no decorrer do ciclo. UFMS, Dourados, 2004-2005.

Tabela 3 - Área foliar (AF), massa fresca (MFF) e massa seca de folhas (MSF), massa fresca (MFE) e massa seca de espigas (MSE) de tansagem, cultivada solteira e consorciada com marcela, sob dois espaçamentos entre fileiras. UFMS, Dourados, 2004-2005.

\begin{tabular}{|c|c|c|c|c|c|}
\hline Variáveis & $\begin{array}{c}\text { AF } \\
\mathrm{cm}^{2} \text { planta }^{-1}\end{array}$ & $\begin{array}{l}\text { MFF } \\
\mathrm{t} \mathrm{ha}^{-1}\end{array}$ & $\begin{array}{l}\text { MSF } \\
\mathrm{t} \mathrm{ha}^{-1}\end{array}$ & $\begin{array}{l}\text { MFE } \\
\text { t ha }^{-1}\end{array}$ & $\begin{array}{l}\text { MSE } \\
\mathrm{t} \mathrm{ha}^{-1}\end{array}$ \\
\hline \multicolumn{6}{|c|}{ Tipo de cultivo } \\
\hline Solteiro & $1.657,65 \mathrm{a}$ & $4,53 \mathrm{a}$ & $0,80 \mathrm{a}$ & $2,33 \mathrm{a}$ & $0,69 \mathrm{a}$ \\
\hline Consorciado & $1.758,62 \mathrm{a}$ & $4,91 \mathrm{a}$ & $0,80 \mathrm{a}$ & $2,86 \mathrm{a}$ & $0,87 \mathrm{a}$ \\
\hline \multicolumn{6}{|c|}{ Espaçamento entre fileiras (m) } \\
\hline $0,40 \mathrm{~m}$ (três fileiras) & $1.896,16 \mathrm{a}$ & $6,13 \mathrm{a}$ & $1,90 \mathrm{a}$ & $3,47 \mathrm{a}$ & $1,04 \mathrm{a}$ \\
\hline $0,75 \mathrm{~m}$ (duas fileiras) & $1.520,09 \mathrm{~b}$ & $3,32 \mathrm{~b}$ & $0,58 \mathrm{~b}$ & $1,73 \mathrm{~b}$ & $0,52 \mathrm{~b}$ \\
\hline C.V. $(\%)$ & 28,89 & 21,30 & 18,80 & 27,38 & 28,89 \\
\hline
\end{tabular}

Médias seguidas pelas mesmas letras, nas colunas, não diferem, pelo teste F, a 5\% de probabilidade.

Tabela 4 - Razão da área equivalente - RAE e Renda Bruta de marcela e tansagem, considerando a massa seca, em cultivo solteiro e consorciado, sob dois espaçamentos entre fileiras. UFMS, Dourados, 2004-2005.

\begin{tabular}{|c|c|c|c|c|c|c|}
\hline \multirow{2}{*}{ Tipo de cultivo } & \multirow{2}{*}{ Espécie } & \multirow{2}{*}{ Espaçamento } & \multirow{2}{*}{$\operatorname{MS}\left(\mathrm{tha}^{-1}\right)$} & \multirow{2}{*}{ RAE } & \multicolumn{2}{|c|}{ Renda Bruta $\left(\mathrm{R} \$ \mathrm{ha}^{-1}\right)$} \\
\hline & & & & & Unitária & Total \\
\hline \multirow{4}{*}{ Solteiro } & \multirow{2}{*}{ Marcela } & $0,40 \mathrm{~m}$ & 0,96 & 1,0 & $7.712,00$ & $7.712,00$ \\
\hline & & $0,25 \mathrm{~m}$ & 1,03 & 1,0 & $8.240,00$, & $8.240,00$ \\
\hline & \multirow{2}{*}{ Tansagem } & $0,40 \mathrm{~m}$ & 1,05 & 1,0 & $6.318,00$ & $6.318,00$ \\
\hline & & $0,75 \mathrm{~m}$ & 0,55 & 1,0 & $3.324,00$ & $3.324,00$ \\
\hline \multirow{2}{*}{ Consórcio $\mathrm{M}_{0,40} \mathrm{~T}_{0,40}$} & Marcela & $0,40 \mathrm{~m}$ & 0,60 & \multirow{2}{*}{1,6} & $4.800,00$ & \\
\hline & Tansagem & $0,40 \mathrm{~m}$ & 0,99 & & $5.955,00$ & $10.755,00$ \\
\hline Consórcio $\mathrm{M}_{0,25} \mathrm{~T}_{0,75}$ & Marcela & $0,25 \mathrm{~m}$ & 1,36 & 2,4 & $10.880,00$ & $14.582,18$ \\
\hline
\end{tabular}

MS = massa seca. RAE = Razão de área equivalente (CAETANO et al., 1999).

Renda bruta calculada com valores de $\mathrm{R} \$ 8,00 \mathrm{~kg}^{-1}$ e $\mathrm{R} \$ 6,00 \mathrm{~kg}^{-1}$ para a marcela e tansagem, respectivamente. Valores de Julho de 2006 , fornecidos pelo Laboratório Industrial Vida e Saúde Ltda - "chá chileno". 
Vieira (1989) destaca que, apenas os valores da RAE não são suficientes para a avaliação do consórcio; é necessário que a RAE seja relacionada com os rendimentos obtidos. Assim, observou-se que, para a marcela, o consórcio $\mathrm{M}_{0,40} \mathrm{~T}_{0,40}$ possibilitou acréscimos de renda bruta por hectare de $\mathrm{R} \$ 2.515,00$ (30\%) e de $\mathrm{R} \$ 6.342,00$ (77\%) para o consórcio $\mathrm{M}_{0,25} \mathrm{~T}_{0,75}$ quando comparado ao melhor tratamento da marcela cultivada solteira $\left(\mathrm{M}_{0,25}\right)$, mostrandose assim vantajoso tanto na razão de área equivalente quanto no rendimento bruto das atividades. Para a tansagem, o consórcio proporcionou maiores rendimentos, com acréscimos de renda bruta por hectare de $\mathrm{R} \$ 4.437,00$ (70\%) e de $\mathrm{R} \$ 8.264,18$ (131\%), para os consórcios $\mathrm{M}_{0,40} \mathrm{~T}_{0,40}$ e $\mathrm{M}_{0,25} \mathrm{~T}_{0,75}$, respectivamente, em relação ao melhor tratamento de tansagem cultivada solteira $\left(\mathrm{T}_{0,40}\right)$.

\section{CONCLUSÕES}

Não houve influência significativa no tipo de cultivo e espaçamento entre fileiras para a produtividade de massa de folhas e flores frescas e secas de marcela. A melhor época de colheita para a marcela foi entre os $180 \mathrm{e}$ 210 dias após transplante.

Para a tansagem não houve diferença significativa entre cultivo solteiro e consorciado, porém o arranjo de três fileiras espaçadas de $0,40 \mathrm{~m}$ apresentou rendimento significativamente superior aos demais.

Considerando os valores da RAE e a renda bruta, concluiu-se que o consórcio entre a marcela e a tansagem mostrou-se efetivo, sendo recomendado o arranjo de duas fileiras de marcela espaçadas de $0,25 \mathrm{~m}$ combinadas com duas de tansagem espaçadas de $0,75 \mathrm{~m}$.

\section{REFERÊNCIAS BIBLIOGRÁFICAS}

ALMEIDA, S. P. de; PROENÇA, C. E. B.; SANO, S. M.; RIBEIRO, J. F. Cerrado: espécies vegetais úteis. Planaltina: Embrapa-CPAC, 1998. 464 p.

CAETANO, L. C. S.; FERREIRA, J. M.; ARAÚJO, M. I. Produtividade de cenoura e alface em sistemas de consorciação. Horticultura Brasileira, Brasília, v. 17, n. 2, p. 143-146, 1999.

CORRÊA, M. P. Dicionário das plantas úteis do Brasil e das exóticas cultivadas. Rio de Janeiro: Imprensa Nacional, 1984. v. 6, p. 187-189.

CORRÊA JUNIOR, C.; MING, L. C.; SCHEFFER, M. C. Cultivo de plantas medicinais, condimentares e aromáticas. 2. ed. Jaboticabal: FUNEP, 1994. 162 p.
EMPRESA BRASILEIRA DE PESQUISA PECUÁRIA.

Centro Nacional de Pesquisa de Solos. Sistema

brasileiro de classificação de solos. Brasília, DF:

Embrapa Produção de Informação; Rio de Janeiro:

Embrapa Solos, 1999. 412 p.

FONT QUER, P. Plantas medicinales: el dioscórides renovado. Madrid: Editorial Labor, 1993. 3 v.

GUILLEN, M. E.; SOUCCAR, C.; LAPA, A. J. Atividade antisecretora e antiúlcera do extrato aquoso de Plantago major L. In: SIMPÓSIO DE PLANTAS MEDICINAIS, 13., 1994, Fortaleza, CE. Anais... Fortaleza: UFC, 1994a.

GUILLEN, M. E.; SOUCCAR, C.; LAPA, A. J. Atividade analgésica e antiinflamatória do extrato aquoso de Plantago major L. In: SIMPÓSIO DE PLANTAS MEDICINAIS, 13., 1994, Fortaleza, CE. Anais... Fortaleza: UFC, 1994b.

LORENZI, H.; MATOS, F. J. A. Plantas medicinais: nativas e exóticas. Nova Odessa: Instituto Plantarum, 2002. 512 p.

MARCHESAN, M.; PAPER, D. H.; HOSE, S.; FRANZ, G. Investigation of the antiinflamatory activity of liquid extracts of Plantago lanceolata L. Phytotherapy Research, v. 12, p. 33-34, 1998.

MATO GROSSO DO SUL. Secretaria de Planejamento e Coordenação Geral. Atlas multireferencial. Campo Grande, 1990.

MOTA, J. H.; NASCIMENTO, E. X.; VIEIRA, M. C.; HEREDIA ZÁRATE, N. A.; YURI, J. E.; CESSA, R. M. A.; NOVELINO, J. O. Produção de biomassa de Pfaffia glomerata em cultivo solteiro e consorciado com Plantago major L. In: CONGRESSO BRASILEIRO DE OLERICULTURA, 46., 2006, Goiânia. Resumos... Campinas: ABH, 2006. p. 2798-2801.

NEGREIROS, M. Z.; BEZZERRA NETO, F.; PORTO, V. C.; SANTOS, R. H. S. Cultivares de alface em sistemas solteiro e consorciado com cenoura em Mossoró. Horticultura Brasileira, Brasília, v. 20, n. 2, p. 162-166, 2002.

PENNA, M. Dicionário brasileiro de plantas medicinais: descrição das plantas medicinais indígenas e das exóticas aclimadas no Brasil. 3. ed. São Paulo: Livraria Kosmos, 1946. 409 p. 
SAKER, M. M.; KAWASHITY, S. A. Tissue culture and flavonoid content of Nepeta and Plantago species endemic in Egypt. Fitoterapia, v. 69, n. 4, p. 358-364, 1998.

SANTOS, R. G. dos; CASTRO, M. S. A. Atividade antinociceptiva do extrato aquoso liofilizado de Plantago major L. ("tanchagem"). In: SIMPÓSIO DE PLANTAS MEDICINAIS, 13., 1994, Fortaleza, CE. Anais... Fortaleza: UFC, 1994.

SIMÕES, C. M. O.; MENTZ, L. A.; SCHENKEL, E. P.; IRGANG, B. E.; STEHMANN, J. R. Plantas da medicina popular no Rio Grande do Sul. Porto Alegre: UFRGS, 1989. $176 \mathrm{p}$.
SULLIVAN, P. Intercropping principles and production

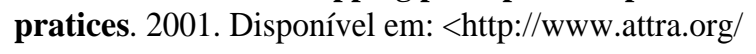
attra-pub/intercrop.html\#abstracts. Acesso em: 3 mar. 2008 .

VIEIRA, C. $O$ feijão em cultivos consorciados. Viçosa: UFV, 1989. 134 p.

VIEIRA, M. C.; HEREDIA ZÁRATE, N. A.; DAL CASTEL, D.; MORAES, T. C.; CAPUANO JUNIOR, J. C. Crescimento e produção de Achyrocline satureioides em função de espaçamentos e arranjos de plantas. In: JORNADA PAULISTA DE PLANTAS MEDICINAIS: NATUREZA CIÊNCIA E COMUNIDADE, 5., 2001, Botucatu. Resumos... Botucatu: Unesp, 2001. v. 1, p. 73. 